María Lourdes Gasillón

Universidad Nacional de Mar del Plata

\title{
DEL NATURALISMO AL NEORREALISMO: BERNARDO KORDON, TESTIGO DE SU TIEMPO
}

Palabras clave: relato, lo cotidiano, marginalidad, viaje, mentira, supervivencia, muerte

\section{Introducción}

Este trabajo intenta analizar algunos textos del escritor argentino Bernardo Kordon, cuyo rasgo común es la elección de personajes y espacios marginales de la sociedad porteña en los años ' 50 y ' 60 . Así, en el corpus seleccionado (más allá de las particularidades de cada caso) el sujeto de la enunciación cuenta, da testimonio y describe, mediante una forma de realismo que no denuncia ni se queja, sino que prefiere mostrar diferentes situaciones cotidianas utilizando un lenguaje simple y común. Como se podrá observar más adelante, el autor presentará distintos tipos de personajes de clases bajas o medio-bajas que configuran un testimonio de las formas de vida de una gran parte de la población de Buenos Aires en aquel momento histórico.

\section{La vida cotidiana en la ciudad}

Para comenzar a hablar sobre Bernardo Kordon es importante tener en cuenta el género literario al que pertenecen los textos a analizar. Siguiendo la postura de Juan José Sebreli (1997: 139-141), estos no son cuentos propiamente dichos, sino relatos, pues tiene las siguientes características particulares: son lineales, no presentan una trama bien definida con un comienzo y un final, tienen una estructura irregular/desordenada, y representan fragmentos concisos, discontinuos y contingentes -al igual que la vida humana-. Al mismo tiempo, aparece la trivialidad como otra cualidad reiterada en su narrativa. Un claro ejemplo de ello es «La última huelga de basureros», donde se muestra como extraordinario un hecho cotidiano en las grandes urbes: la huelga de los recolectores de basura; por lo tanto, según Sebreli, «lo cotidiano es [...] por demasiado conocido, lo desconocido» (1997: 140). En este relato narrado en tercera persona omnisciente (a veces, alternada con una primera persona plural), se habla sobre una huelga de basureros que está localizada en un tiempo y lugar precisos: del 22 de diciembre hasta los primeros días de enero en la ciudad de Buenos Aires, y los sucesos son contados a la manera de una crónica policial de diarios:

El hecho se produjo en la mañana del 22 de diciembre. El camión Dodge unidad $N^{\circ} 207$ de la Dirección General de Limpieza se encontraba en plena labor por la calle Arenales. [...] El vehículo estaba detenido en el centro de la calzada y este detalle provocó la protesta de Isidoro Camuso, industrial de 45 años, que conducía su Valiant chapa 597.905 de la ciudad de Buenos Aires. 
[...] Justamente en ese instante los recolectores transportaban los enormes tachos pertenecientes a los edificios señalados por los números 1856, 1858, 1845 y 1849 de la calle Arenales, que no cuentan con sistemas de incineración de residuos. Si hemos señalado que el conductor detuvo el camión en medio de la calzada, obstruyendo el paso al tráfico y se mostró impasible a los requerimientos del automovilista demorado [...]. (Kordon, 1975: 345)

En este sentido, puede observarse la enumeración de los detalles precisos de marcas y patentes de los automotores, los números de las unidades transportadoras y su recorrido por las calles de la ciudad, tal como se presentan en las páginas de las secciones policiales de los periódicos, y cuyo narrador es homologable a la figura de un periodista que comenta lo sucedido a partir de fuentes testimoniales orales. Simultáneamente, dicho medio de comunicación reaparece nombrado más adelante en el relato junto a otros que se están difundiendo a nivel masivo en la sociedad argentina de los '50-'60: la radio y el teléfono, y las cuestiones asociadas a la libertad de prensa y las mentiras que pueden decirse en los medios.

Por otra parte, a través de un lenguaje coloquial y característico de la población porteña, el texto describe los sentimientos - pavor, odio y humillación-del industrial Isidoro Camuso, uno de sus protagonistas que siente agredido su honor por la resistencia de los huelguistas. Tal factor es el desencadenante de varias muertes y la persecución de los obreros a cargo de la policía, utilizando para describir la escena imágenes de movimiento y velocidad (también en la divulgación de la noticia):

La policía fue alertada. Un radio patrulla desembocó a toda velocidad por la avenida Belgrano y persiguió al camión basurero que huía hacia el sur [...]. Los testigos declararon que, en vez de frenar, el Dodge aceleró para embestir con mayor fuerza al coche policial. De sus planchas retorcidas se retiraron tres cadáveres y un herido grave [...]. Se produjeron cuatro muertos (entre los transeúntes), pero protegido por su estructura de acero el camión prosiguió su carrera. Se extendió entonces el rumor que por razones políticas y sindicales había orden de detener o balear a todos los basureros. Inmediatamente la noticia fue divulgada por una radio uruguaya y todos los camiones recolectores de basura $[. .$.$] se dirigieron apresuradamente$ hacia los basurales del sur. (Kordon, 1975: 348)

El campo semántico relacionado con la recolección de residuos (que incluye las palabras gremio, obreros, sindicatos, huelga) lentamente se contamina con la jerga policial/ delictiva y después, el episodio toma otra connotación, pues en un comienzo se trata de un hecho común, pero poco a poco este va adquiriendo importancia y se convierte en algo descomunal que invade la capital del país. Es decir, un conflicto gremial puntual, cotidiano y minúsculo se transforma en una cuestión general que afecta a la totalidad de la población de Buenos Aires y ello es perceptible en la recurrencia del pronombre indefinido todos y similares como el pronombre tanto y el adverbio totalmente. De esta manera, la basura está personificada como algo que se acumula rápidamente, es indestructible y fagocita a todos los sectores ciudadanos -incluso a los funcionarios políticos y al ejército, al que se alude con una marca de época: el golpe militar- por completo. Todo desaparece 
y Buenos Aires vuelve a ser la pampa desolada que encontraron los conquistadores españoles antes de su fundación:

[...] la basura comenzó a crecer tanto en los interiores como en las calles. Ambas corrientes se unían en puertas y ventanas con un siniestro sonido de deglución.

[...] la basura cubrió totalmente las torres de transmisión. [...] trémula fuerza fosforescente sin pesantez engulló a la caravana de fugitivos y fue borrando el recuerdo de la ciudad. (Kordon, 1975: 351-352)

\section{La ciudad marginal}

Asimismo, la velocidad, el tiempo fugaz y la desaparición de los personajes están presentes en «El remolino» con otras particularidades. En este caso, aparecen dos remolinos: uno, vinculado a la vida tranquila del campo, la pesca, lo inofensivo y la infancia; otro, tiempo después, ligado a la multitud, el movimiento giratorio, el torbellino y el peligro de la gran ciudad, donde se debe subsistir como sea. En este sentido, se alude a la migración de los habitantes de las provincias a Capital Federal en busca de un trabajo digno y bien remunerado. No obstante, aquí se relata un ejemplo específico-que tiene un tono de generalidad-, cuya protagonista es Hermenegilda, una joven del interior con piel oscura que se dedica a la prostitución:

-El remolino es lo mejor para pescar-le enseñaba el Beto-. [...]

Aquí en la ciudad encontró el remolino en las estaciones ferroviarias, en algunas plazas y en muy pocas calles. [...] Aquí en la ciudad el peligro se dice hacer bandera, es decir llamar la atención. El remolino humano trae solitarios hombres-peces, secos bagres o grasosos pacús, pero también tiras pechadores y charlatanes de vana degeneración que preguntan y desaparecen. (Kordon, 1975: 257-258).

El narrador en tercera persona -omnisciente en algunas partes, cuando describe las impresiones del cliente de Hermenegilda- relata los hechos con precisión espacial, ya que hace referencias concretas y reales a calles y barrios de Buenos Aires, matizándolos con la descripción minuciosa del encuentro de la prostituta con el cliente y sus asesinos, y el diálogo entre los personajes de ambas situaciones. El primero de estos núcleos narrativos focaliza el detalle del cuerpo visto como un objeto sexual de compra y venta, que sirve para satisfacer al hombre por un instante:

Con el gesto automático del cierre relámpago se quitó el vestido y quedó en calzones y sostén blancos que contrastaban con el cuerpo cobrizo, casi negro. [...] Negra con pies grandes y piernas anchas, de niñez descalza y caminadora. Al soltarse el corpiño resbalaron los pesados pechos de enormes pezones morados. Aquello prometía como un inerme objeto sexual [...]. (Kordon, 1975: 259)

En la anterior cita y a lo largo del relato se pone el énfasis en la negrura de la piel de la muchacha que intriga y atrae al hombre en principio, pero luego esa condición le 
provoca repulsión al darse cuenta de que estaba con una cabecita negra: una expresión que durante la época del presidente Juan Domingo Perón, en Argentina, se utilizaba para hacer referencia a la gente de las provincias que se trasladaba masivamente hacia Buenos Aires en busca de trabajo. Hay una contraposición fuerte en el discurso del narrador cuando caracteriza al porteño (con cualidades positivas) y al provinciano, quien encarna lo negativo, lo oscuro, lo maligno porque viene a quitar las oportunidades laborales a los blancos, a robar y a hacer daño. Esta clase de inmigrante comienza a instalarse en la ciudad-puerto durante las últimas décadas y cuenta con derechos constitucionales, pero el ciudadano capitalino los desprecia, oprime y descalifica agresivamente (Sebreli, 1997: 150-151):

Cabecita, cabecita negra, salida de la tierra y color tierra como un gusano, el pensamiento torcido de quien viene a arrebatar la tranquilidad y los bienes y hasta la salud del hombre blanco de la ciudad.

[...] El porteño es limpio, rosado, rico, hospitalario. Su ciudad fue el templo de virtudes consagradas en todo el mundo, hasta que el cabecita trajo la doblez, la rapiña, el resentimiento social, todo aquello oscuro como su piel. (Kordon, 1975: 260-261)

Algo similar ocurre hacia el final en el encuentro casual y peligroso de la mujer con unos agresores desconocidos, quienes por efecto de la droga o simplemente por humillarla, le roban su dinero, la insultan y la matan sin piedad:

-Mostrale el bufoso a la negra para que aprenda. [...]

-Dejá esa negra de mierda y vamos a la Panamericana -se lamentó el flaquito-. [...]

-[...] Largá esa cabecita -rogó el flaquito-. (Kordon, 1975: 263)

Por otra parte, en su trabajo cotidiano ella interpreta un papel frente al cliente a cambio de dinero, limitándose a decir lo estrictamente necesario y resguardando su verdadera identidad a través de mentiras que la definen como una cuentera, al igual que otros personajes de la narrativa kordoneana. En definitiva, expresa datos falsos para construir su doble o alter-ego:

-¿De dónde sos?

[...] -De aquí cerca: santafecina soy. (Kordon, 1975: 259)

-¿Cómo te llamás? -preguntó el hombre en otro vano intento de detener el vórtice del remolino que ya lo tragaba.

Mientras se ponía los zapatos ella dijo Nelly o Betty, cualquier nombre de batalla que no significaba gran cosa [...]. (Kordon, 1975: 260)

Además, aparece el lenguaje coloquial rioplatense de clase baja o medio-baja al que pertenece esta mujer (como «¿Anduvistes con ese atorrante del Beto?» (Kordon, 1975: 257)) y ciertas convenciones de época que debe respetar debido a su condición femenina; por ejemplo, la parte de un café destinada a las familias: 
Vio una mesa recién desocupada en el café de Pueyrredón y Sarmiento y allí se sentó. Era el reservado para familias, caso contrario no se hubiera atrevido a entrar. (Kordon, 1975: 261)

Retornando al planteo de Sebreli (1997: 164-167), los hombres a los que afecta el remolino de la ciudad son mayormente los marginados sociales que realizan trabajos fuera de la ley o del código de la burguesía, y cuya vida es fragmentaria ya que no tienen una relación fija con nadie o un hogar determinado para vivir. Estos nómades recorren la urbe e intentan evadir así su soledad. En el relato analizado, se trata de un personaje doblemente desplazado: prostituta y cabecita negra, quien camina mucho por los barrios y finalmente, intenta llegar a su vivienda, también ubicada en un espacio totalmente marginal (la villa) y alejado del centro (el suburbio o arrabal):

No temió como otras veces llegar tarde a la villa donde vivía. Resolvió dar otra vuelta antes de volverse a casa. Le tocó caminar mucho. El remolino de la estación Once abarcaba la avenida Pueyrredón hasta llegar a Corrientes, y por Rivadavia hasta Congreso. (Kordon, 1975: 262)

\section{En busca de nuevas oportunidades}

El tema del viaje a la ciudad en busca de oportunidades se reitera en el relato «Fuimos a la ciudad». En este caso, de manera similar a la temática de un tango de principios de siglo, se narran las peripecias de Florinda, quien sufre un desengaño amoroso y quiere mejorar su condición económica yendo a Capital Federal (al igual que Hermenegilda), pero allí cambia su personalidad para adaptarse a su nuevo ambiente social. Dicho personaje femenino al igual que la madre y otras hermanas es visto negativamente por el narrador, quien está relacionado afectivamente con ellas pues es un personaje más de la historia (el hermano menor). Así, esta primera persona protagonista -que narra en singular cuando se refiere a sí mismo o en plural, cuando incluye a su familia- se construye discursivamente como un buen hijo que no abandona a su padre enfermo a pesar de vivir unos días en Buenos Aires y por eso, se diferencia de las mujeres que lo rodean:

Por eso el viejo andaba sentido de tanta ingratitud y sólo quedaba yo para traer unos pocos pesos que cada día alcanzaba para menos. Mi hermana contestó que el viejo era un egoísta, que nunca le importó que sus hijas anduvieran sin zapatos y se les formaran costras en las patas, y por eso se fueron todas. (Kordon, 1975: 12)

Entonces dejó de hacerse el dormido y me dijo que yo era un buen hijo. (Kordon, 1975: 19)

¡Y yo que quise darle la sorpresa de volver para ayudarle!

-Hubiera sido lindo para él -dijo el Pancho-. Eso justamente lo tenía jodido: que lo dejaron solo. (Kordon, 1975: 25)

Si bien este muchacho debe trabajar desde niño junto a sus hermanas para mantener el hogar y también intenta adaptarse, como lo hace su familia, a las estrategias de supervivencia de la ciudad, no cambia completamente porque siempre siente cariño y respeto por la figura paterna. Manifestando una actitud distinta a la de Florinda, menosprecia la 
nueva personalidad de su hermana, de la que quiere vengarse en una oportunidad (al igual que el Cholo), y mira negativamente el lenguaje burlón de los porteños. Sin embargo, en cierto modo él también adopta la denominada viveza criolla en la ciudad y abandona su antigua ingenuidad. En otras palabras, el protagonista se convierte en un pícaro urbano que, acompañado por su socio Tito el Patas Chuecas, aprende a sobrevivir en la calle mediante la interpretación de un papel que provoca lástima en los transeúntes. Con esas limosnas comienza a disfrutar de comidas que antes no tenía, y que se contraponen a las de su vida en el interior:

Esa mesa parecía de velorio, dos botellas de vino y muchas cosas ricas que mi hermana trajo de Buenos Aires [...]. (Kordon, 1975: 14)

Mamá sirvió la sopa. (Kordon, 1975: 17)

Nos sentamos en una lechería. Pedimos café con leche y doble porción de medialunas con dulce de leche. Después contamos la plata. [...] Entramos en una heladería. Comimos helados tras helados, de siete clases. (Kordon, 1975: 21-22)

Todas estas estrategias de supervivencia y sabiduría callejera que desarrollan el protagonista y sus hermanas, de las cuales una de ellas también se dedica a una profesión marginal: la prostitución como en el caso de Hermenegilda, está enmarcado por un recorrido/movimiento urbano de estos personajes por distintas calles y zonas de la Capital, desde su llegada en tren a la misma:

Subimos en el ómnibus 150 y nos bajamos en Congreso para caminar por la calle Rivadavia. (Kordon, 1975: 21)

[...] me contó el recorrido que hacía mi hermana por Rivadavia, desde Congreso hasta Once, y después por Pueyrredón hasta Sarmiento. Tuve ganas de preguntarle otras cosas, pero la calle terminaba de enseñarme la lección: calladito y con cara de ángel todo iba a salir de lo mejor. (Kordon, 1975: 22)

Finalmente, cabe agregar que a lo largo del relato se articula la narración y el diálogo entre los personajes, optándose por un lenguaje coloquial de clase baja, un vocabulario grosero y el uso del voseo en algunas oportunidades:

[...] mi madre movía la cabeza como diciendo que sí, que yo era muy pelotudo. (Kordon, 1975: 13)

-¿Me acompañás?

-¿A dónde? -y se le torció la jeta pintada. (Kordon, 1975: 14)

-¿Qué hacés ahí? -me retó el Cholo-. ¿Andás espiando?

-Me duele la barriga -se me ocurrió. (Kordon, 1975: 16)

\section{El camino de la vida}

El anterior relato culmina con un final trágico: la muerte del padre del narrador. Dicha temática se repite en otros textos de Kordon y afecta a sus personajes más importantes. Uno 
de ellos es «Estación terminal», donde la narración está a cargo de un individuo en sus últimos momentos antes de morir. Es decir, utilizando la primera persona singular, el protagonista describe sus sensaciones y sentimientos previos a la muerte a través de sus sentidos:

Me estoy muriendo aquí tirado en el sofá y tengo miedo de la crueldad de las cosas. (Kordon, 1975: 353)

Si las cosas no se preocupan por mí, en cambio yo sufro por ellas. Siento la aspereza de la tela del sofá, veo el veteado de la madera y la luz en el cristal. Pues todo comienza y termina con los sentidos. Porque yo y el mundo no morimos juntos. (Kordon, 1975: 354)

Abro los ojos y trato de ver. Los sonidos me envuelven y revientan en mis oídos. [...] Muero rodeado de libros y no recuerdo ninguno. [...] Ahora le digo basta a la vida, pero mis sentidos se aferran a las cosas. (Kordon, 1975: 356)

Valiéndose del tacto, la audición y la vista, emite un discurso sobre las cosas materiales y se detiene en una codorniz de marfil que trajo de su viaje a China. Luego de realizar un detalle sensorial amplio de este objeto decorativo y mediante el mismo -asociado a una gallina-, su mente conecta uno de sus recuerdos pasados con el presente que vive. Para este narrador, los objetos y el arte son inmortales a diferencia de los humanos, como él mismo, que está en trance de morir. En este retroceso temporal, su pasado y su actualidad se metaforizan a partir de homologar el viaje en un colectivo con la vida misma, los cuales tienen un punto final/destino: la estación terminal (cuyo adjetivo da cuenta del término o fin de algo) en el primer caso, que está en los suburbios, los arrabales, las afueras de la ciudad, y la muerte, en el segundo. En ese movimiento/vagabundeo urbano, se hacen presentes los diálogos entre los pasajeros, el uso de la primera persona plural para expresar la experiencia grupal, se detallan líneas precisas de colectivos y sus recorridos, la actividad de los vendedores ambulantes en este tipo de transportes y la carga semántica fuerte de la palabra final al ser reiterada muchas veces:

Muchas veces me propuse tomar el colectivo 252 hasta el final del recorrido. [...] El colectivo 252 -amarillo con firuletes negros y colorados asoma cautelosamente su trompa por la esquina de Anchorena. Estoy pues en el barrio del Abasto, en la calle San Luis. (Kordon, 1975: 356)

Sonreíamos a modo de disculpa y esperamos el próximo coche, con la determinación de llegar al final del recorrido. (Kordon, 1975: 357)

Aparecieron los vendedores para perorar y repartir lapiceras, estampas religiosas, turrones de maní, viejas revistas infantiles o de modas. [...] Parecen conocer las particularidades de los pasajeros de la línea 252, gente dispuesta para un viaje sumamente largo y de problemático final. (Kordon, 1975: 358)

En último término, al comenzar el texto, el propio Kordon hace una autorreferencia al escribir las iniciales $b k$ (las mismas de su nombre) para aludir nuevamente a un narrador personaje como doble o alter-ego del autor, y a la vez, a una de sus obras: «Bairestop» (1975), pero en expresiones separadas que remiten también al destino -baires- del viaje 
en colectivo (ciudad de Buenos Aires) e incluso de su propia vida, y al final/la última parada/la muerte del protagonista -stop-:

Pues el mensaje recibido es claro: destino baires. Un destino como cualquier otro: rigurosamente casual. Texto a transmitir: stop. (Kordon, 1975: 354)

\section{Otras formas de comunicación}

De la misma manera, en el relato «El sordomudo» se retoma el asunto de la muerte, pero en una veta más policial y delictiva, al igual que en «El remolino», pues el joven discapacitado es víctima de un asesinato a manos de Severino, un ex-boxeador convertido en linyera. Una vez más, la literatura de Kordon prefiere un personaje marginal en la sociedad, que vagabundea libremente por Buenos Aires y el país. En este punto, se asemeja al camionero que vagabundea por distintos lados debido a su oficio de transportador de mercaderías, y además, ambos se encuentran de manera azarosa y fortuita. En compañía de Cachito, realiza diferentes recorridos por las calles de la ciudad y sus regiones suburbanas, que están muy bien detalladas por el sujeto de la enunciación al igual que en otros textos de este escritor argentino:

Al día siguiente volvieron al sur. Después de entregar mercaderías por los alrededores de Constitución, tomaron por la avenida Montes de Oca y cruzaron el Riachuelo por el puente Pueyrredón. [...] Aceleraron por la avenida Pavón. (Kordon, 1975: 275)

Días después fueron a Retiro con una carga de bobinas. Tomaron la avenida que se interna por el flanco del ferrocarril Belgrano. (Kordon, 1975: 277)

Esta narración -más extensa que las anteriores- está dividida en seis partes fragmentarias, donde se narran en tercera persona las experiencias, sentimientos y sensaciones de Aristóbulo y su ayudante sordomudo. Tal discapacidad imposibilita la comunicación verbal entre ambos, si bien el texto cuenta con bastantes diálogos entre el camionero y otros personajes, en los que aparece el lenguaje coloquial y el voseo rioplatense. En su lugar, se apunta a la profundización de otras formas comunicativas como el lenguaje de señas/gestos, los dibujos, las imágenes auditivas, las exclamaciones y la interpretación de sensaciones diversas:

El mudo los señaló:

-¡Uuuu! -hizo con los ojos muy abiertos de admiración.

- ¿Qué te pasa, pibe?

El mudo insistió en mostrar el tren que desaparecía hacia el sur.

-¡UUU! -aulló como un lobo. (Kordon, 1975: 273)

Aristóbulo se preguntó qué representaría para el sordomudo el paso del tren. Se le ocurrió que todo [...] debía de ser fantasmas. Por primera vez en su vida se imaginó las sensaciones de otro ser y se esforzó en comprenderlas. ¿Y si él se volviese sordo algún día? [...] El muchacho retiró de un bolsillo dos hojas de papel. Mojó con la lengua la punta del lápiz y se aplicó en trazar rápidamente un dibujo. (Kordon, 1975: 275-276) 
Paralelamente, la caracterización psicológica de Aristóbulo se modifica a lo largo de la narración, ya que en un principio es soberbio, se cree superior a su ayudante, lo desprecia en cierta manera y se compadece de él por su dificultad. Sin embargo, después siente cariño hacia el muchacho y tristeza por su asesinato, al mismo tiempo que va perdiendo también la capacidad de hablar y escuchar, mimetizándose con Cachito, volviéndose más humano y más perceptivo al desarrollar otros sentidos:

-Yo también soy como sordomudo -se dijo en vos alta.

El muchacho lo vio hablar y le hizo un gesto de incomprensión.

-Así es -insistió el camionero-. No entendemos nada de nada. (Kordon, 1975: 283)

-¿Qué te pasa? ¿Te contagió el mudo? ¿O no sabés que aquí te vamos a hacer hablar de cualquier modo? (Kordon, 1975: 283)

\section{La mentira, una estrategia de supervivencia}

Continuando el abordaje por la literatura de Kordon, nuevamente el final trágico de un personaje reaparece en otra de sus obras fundamentales: «Toribio Torres, alias 'Gardelito'». Ya en este título, está presente una de las características principales del personaje central: la palabra alias, que significa de otro modo, por otro nombre y se relaciona con un doble comportamiento de Toribio, o sea, su figura como doble o alter-ego del autor real y también, como un cuentero que construye narraciones, engaños y personajes constantemente para sobrevivir en la calle:

- ¿Vivís lejos? -preguntó la mujer. Empleaba un tuteo forzado y desdeñoso. Y Toribio mentía, mentía siempre, más por sistema que por conveniencia.

-Vivo en Avellaneda. (Kordon, 1961: 47)

'Soy un cuentero', pensó con repentina alegría. 'Puedo engañar a este Fiacini como engañé a Leoncio. Puedo engañar a cualquiera'. Y esa seguridad crecía en él como un canto interior. (Kordon, 1961: 97)

Respecto de este punto, Sebreli (1997: 152-155) agrega que el personaje, al igual que la prostituta Margot (como la del famoso tango) y los diferentes nombres/máscaras que adopta para trabajar con los hombres, aparenta ser algo que no es: un cantante reconocido, de ahí su pseudónimo Gardelito - con el sufijo diminutivo que lo pone por debajo del cantante real y denota su edad-. Es decir, Toribio es un cuentero y un artista que pretende cantar tangos, pero como no lo logra, continuamente representa una comedia frente a otros - por ejemplo: la mujer elegante, el cocinero Leoncio, la dueña de Pucky, etc.-. Engaña a sus víctimas siguiendo sus planes bien elaborados para sobrevivir en Buenos Aires; y sus mentiras son una forma de arte que le permiten salir beneficiado de cualquier situación problemática. De esta manera, se constituye como un pícaro urbano o antihéroe que aprendió de la calle a engañar a las personas y a traicionar a sus compañeros si lo necesita, como por ejemplo, Alberto. 
Pese a esto, hacia el final, el propio Torres será una víctima de la traición de Picayo y la venganza de Fiacini -otro pícaro estafador y vividor-. En realidad, para Toribio el mal no es el mejor camino y se da cuenta de que está solo en la gran ciudad, por ello quiere afirmarse/redimirse como persona y buscar en Picayo a un compañero que lo respalde en su nueva vida sin mentiras y su arrepentimiento. No obstante, la parodia está en ese punto: el pícaro burlador es burlado por sus pares al decir la verdad por primera vez, y debe pagarlo con su vida -nuevamente, el final trágico para el protagonista-. Así se expresa el sujeto de la enunciación ante este aspecto:

Sintió la detonación como un golpe de gong en el cerebro. Y fugazmente tuvo la revelación de perderlo todo porque una vez dijo la verdad, cuando se sintió muy solo y buscó un amigo. (Kordon, 1961: 118)

En tercera persona, el narrador -por veces omnisciente- de este largo relato o nouvelle construye una biografía (Sebreli, 1997: 151) del personaje dividida en tres partes y con la particularidad de la preeminencia del diálogo entre los personajes, a modo de una representación teatral urbana en la que cada uno desempeña un papel para obtener un beneficio económico. En dicha historia de aventuras fugaces, Gardelito es un desarraigado social que viaja del interior a Buenos Aires para mejorar su condición, pero únicamente intenta sobrevivir como puede, sin esforzarse demasiado y vagando por las calles de la Capital (que conforman referencias espaciales detalladas y reales), sus barrios, conventillos llenos de mugre y olor, y hoteles o pensiones de baja categoría que va encontrando a su paso en zonas marginales/bajas de la urbe, pues no tiene un lugar fijo para vivir después de abandonar a su familia obrera:

-¿En qué parte de Talcahuano vivís?

-En el Hotel Italia, cerca de Sarmiento. (Kordon, 1961: 81)

Pagó el café y echó a andar hacia el sur.

Repentinamente le dominó un cansancio deprimente al atravesar la Plaza Constitución. Arrastraba los pies sobre los guijarros del sendero. [...] El hecho de andar por ese sendero polvoriento le trajo el recuerdo de sus largas caminatas de muchacho por los parques de $\mathrm{Pa}-$ lermo [...]. Era el muchachito provinciano, y repentinamente las calles del barrio de Palermo lo atraparon y empezó a sentirse otro. Se hizo agresivo porque sentíase en un medio hostil, y comenzó a elucubrar y mentir porque lo abrumaba la sensación de su debilidad. (Kordon, 1961: 109)

\section{Conclusiones}

A modo de cierre del presente trabajo, se observó una constante en las narraciones elegidas: la aparición de personajes desclasados y/o discriminados por la sociedad burguesa de los años ' 50 y ' 60 , particularmente, los vagabundos o personajes que se convierten en nómades a partir de sus viajes y recorridos por la ciudad de Buenos Aires. Por esta razón, podría decirse que el autor toma algunos aspectos minúsculos de lo que Mijail Bajtín (1990: 200-201) denomina novela de vagabundeo, pues los protagonistas se mue- 
ven por espacios disímiles y viven aventuras diferentes, con lo cual el artista expone y describe la heterogeneidad social y espacial de la Capital Federal, los grupos de individuos que conviven en ella (casi todos marginados) y sus formas de vida -los recolectores de basura, los cuenteros, las prostitutas, los que presentan una discapacidad física, etc.-. Este detalle de la realidad argentina de esa época está asociado en varios ejemplos a héroes o anti-héroes que sobreviven de cualquier manera: engañando, asesinando, robando, etc. - estando fuera de la ley-a sus semejantes y asimilando la tradición de la picaresca europea.

En ninguno de los relatos analizados, se evidencia una actitud moralizante, sino un realismo que exhibe la conciencia de época marcada por los encuentros y desencuentros de personajes que están conformes con la vida que les toca en suerte, generalmente, y que se producen en un ámbito urbano y cotidiano muy bien descripto a partir de indicios de locaciones espacio-temporales precisas -muchas veces en lugares periféricos-. Con ese objetivo, Kordon suele detenerse en los procesos migratorios de personas del interior a Buenos Aires para encontrar ciertas oportunidades, acompañando las descripciones minuciosas con imágenes olfativas y gustativas que complementan la fragilidad existencial de los antihéroes.

\section{BIBLIOGRAFÍA}

Abbate, F. (2004): «La exploración de líneas heterodoxas. Enrique Wernicke, Bernardo Kordon, Arturo Cerretani, Alberto Vanasco». En: Noé Jitrik (dir.): Historia crítica de la literatura argentina. Buenos Aires: Emecé, 573-597.

Bajtín, M. (1990): «La novela de educación y su importancia en la historia del realismo». En: Estética de la creación verbal. México: Siglo XXI, 200-247.

Kordon, B. (1975): Todos los cuentos. Buenos Aires: Corregidor.

Kordon, B. (1961): «Toribio Torres, alias Gardelito». En: Vagabundo en Tombuctú, alias Gardelito y otros relatos. Buenos Aires: Losada.

Olguín, S., Zeiger, C. (1999): «La narrativa como programa. El realismo frente al espejo». En: Noé Jitrik (dir.): Historia crítica de la literatura argentina. Buenos Aires: Emecé, 377-401.

Sebreli, J. (1997): «Los relatos de Bernardo Kordon». En: Escritos sobre escritos, ciudades bajo ciudades. Buenos Aires: Sudamericana. 


\section{OD REALIZMA DO NEOREALIZMA: BERNARDO KORDON, PRIČA SVOJEGA ČASA}

Ključne besede: zgodba, vsakdanjost, marginalne skupine, potovanje, laž, preživetje, smrt

Avtorica v prispevku analizira pripovedna besedila argentinskega pisatelja Bernarda Kordona, katerih skupna značilnost je prisotnost marginalnih oseb in prostorov, značilnih za Buenos Aires v 50' in 60' letih prejšnjega stoletja. Pisatelj v izbranih besedilih (prek pripovedovalca in oseb) pripoveduje, priča in opisuje na realističen način, s katerim ne obtožuje ali kritizira, temveč želi pokazati različne vsakdanje situacije, tudi z rabo preprostega in grobega jezika. Junaki so v glavnem pripadniki nizkih ali srednjih slojev in predstavljajo način življenja velikega dela buenosaireškega prebivalstva $\mathrm{v}$ tistem zgodovinskem obdobju. 